\title{
Investigation of morphology associated with biporous polymeric materials obtained by the double porogen templating approach
}

Sarra Mezhoud, ${ }^{a, b, c}$ Benjamin Le Droumaguet,,${ }^{a *}$ Patrick Aimedieu, ${ }^{b}$ Vincent Monchiet ${ }^{c}$ Michel Bornert, ${ }^{b}$ and Daniel Grande ${ }^{a, *}$

${ }^{a}$ Université Paris Est, Institut de Chimie et des Matériaux Paris-Est (ICMPE), UMR 7182, CNRS-UPEC, 2 rue Henri Dunant, 94320 Thiais, France

${ }^{b}$ Université Paris Est, Laboratoire Navier, UMR 8205 CNRS-Ecole des Ponts ParisTech-IFSTTAR, 6/8 avenue Blaise Pascal, 77455 Marne-la-Vallée Cedex 2, France

${ }^{c}$ Université Paris Est, Laboratoire de Modélisation et de Simulation Multi-Echelle, UMR 8208 CNRS-UPECUPEM, 5 boulevard Descartes, 77454 Marne-la-Vallée Cedex, France

E-mail of authors:

mezhoud.sarra@icmpe.cnrs.fr, ledroumaguet@icmpe.cnrs.fr, patrick.aimedieu@enpc.fr, vincent.monchiet@univ-paris-est.fr, michel.bornert@enpc.fr, grande@icmpe.cnrs.fr

*Corresponding authors:

Dr. Benjamin Le Droumaguet, Dr. Daniel Grande

Phone: +33 (0)149781177

Michel BORNERT

0000-0002-6964-5793

Daniel GRANDE

0000-0002-9987-9961

Benjamin LE DROUMAGUET

0000-0002-5757-3606

Vincent MONCHIET

0000-0002-1571-6939? 


\section{ABSTRACT}

Doubly porous polymeric materials were prepared from 2-hydroxyethyl methacrylate (HEMA) through the double porogen templating approach. One such approach required the use of a macroporogenic agent, i.e. $\mathrm{NaCl}$ particles, and a porogenic solvent. To this purpose, sieved $\mathrm{NaCl}$ particles of different size ranges were used $(125-200 \mu \mathrm{m}, 200-250 \mu \mathrm{m}$ and 250-400 $\mu \mathrm{m})$, either sintered through Spark Plasma Sintering or non-fused, in conjunction with a porogenic solvent, i.e. isopropanol. After removal of the, the resulting biporous scaffolds were finely characterized in terms of porosity by scanning electron microscopy (SEM), mercury intrusion porosimetry (MIP), and nitrogen sorption porosimetry. All the obtained results indicated higher porosity ratios and specific surface areas for doubly porous materials prepared from SPSmediated sintering of macroparticles, thus demonstrating the crucial role of macroporogen packing on the resulting porosity features. Indeed, a higher compaction of $\mathrm{NaCl}$ particles generated fewer interstitial voids between adjacent inorganic particles and thus afforded a higher porosity (87\% porosity ratio) in the resulting porous material as compared to the corresponding analogue prepared from non-sintered $\mathrm{NaCl}$ particles (80 \% porosity ratio). A complementary 3-D imaging of the microstructure by means of X-ray computed microtomography $(\mu \mathrm{CT})$ but also synchrotron $\mu \mathrm{CT}$ analysis qualitatively confirmed these findings. The macroporogen size was also considered to be a crucial parameter regarding the porosity features, as increasing macroporogen sizes were notably associated with increasing porosity ratios. Finally, swelling of those mono- and biporous materials was investigated. The interconnection in the higher porosity level were notably evaluated and it was observed that the water uptake of biporous PHEMA scaffolds comprising an interconnected higher porosity level can be as high as $\sim 2500 \%$.

Keywords: doubly porous polymeric materials, porogenic agents, Spark Plasma Sintering, Xray computed microtomography 


\section{Introduction}

Porous materials with bimodal porosity have been the subject of intense research for many years, mostly because of their large range of applications. They are widely used as innovative materials in many areas, including civil engineering, separative sciences [1-3], tissue engineering [4] and drug delivery applications [5]. In the area of tissue engineering for instance, the first porosity level with pore sizes over $100 \mu \mathrm{m}$ should allow for efficient seeding and proliferation of suitable cell lines through the material, while the second one with pore sizes lower than $1 \mu \mathrm{m}$ may permit to improve the nutrient and waste flow within the material when the macropores are clogged at the last stage of the cell culture. In engineering applications, the larger porosity level would allow macromolecules flow through the material, while the smaller porosity level would be dedicated to the passage of smaller molecules or play an important role regarding filtration issues [5-7].

In this context, different strategies have hitherto been developed for the development of polymeric materials exhibiting a double porosity. Temperature-induced phase separation (TIPS) has recently been reported by one of our groups for the design of poly(2-hydroxyethyl methacrylate) (PHEMA)-based scaffolds by using a co-solvent mixture constituted of water and 1,4-dioxane. Solidification process occurred by quenching the PHEMA/co-solvent mixture at a given temperature, and subsequent freeze-drying permitted to obtain biporous PHEMA frameworks [8]. TIPS in conjunction with particle leaching has also been reported earlier for the synthesis of poly(L-lactide)- (PLLA) [9], gelatin- [10] or poly(lactide-co-glycolide)(PLGA) [11] based scaffolds. In these studies, poly(ethyl methacrylate) (PEMA), paraffin, and sucrose spheres (with different diameter ranges) were used as macroporogens, while dioxane, ethanol/water or chloroform allowed for the formation of a lower porosity level during the TIPS process. Furthermore, the High Internal Phase Emulsion (HIPE) technique was also used to obtain PHEMA-based materials with a hierarchical porosity [12-15]. The first porosity level was generated by the removal of an organic porogenic solvent, while the second one resulted from the interconnections between adjacent macropores. The design of doubly porous polymeric materials was also investigated by a double porogen approach involving a macromolecular porogen, i.e. poly(ethylene glycol), in combination with $\mathrm{NaCl}$ particles to obtain PLLA scaffolds [16]. Finally, in the past few years, doubly porous PHEMA materials were produced via a double porogen templating approach through the use of inorganic $\mathrm{CaCO}_{3}$ $[17,18]$ and $\mathrm{NaCl}[19,20]$ particles or PMMA beads $[17,18]$ to generate the macroporosity. The second porosity level was obtained by using either hydroxyapatite nanoparticles [18] or porogenic solvents, such as alcohols [17-19]. 
In this study, we aim to get a thorough insight into the morphology of model biporous PHEMAbased materials obtained by the double porogen templating approach. In order to generate the macroporosity, either SPS-sintered $\mathrm{NaCl}$ particles or non-sintered ones are used as the macroporogenic template, while the second porosity level is generated by using a porogenic solvent through phase separation during the material formation by free-radical copolymerization. We focus our investigation on tuning the macroporosity, and more specifically on the effect of $\mathrm{NaCl}$-template packing and particle size on porosity features associated with biporous frameworks. The porosity of the as-obtained porous materials is carefully characterized by means of mercury intrusion porosimetry (MIP), scanning electron microscopy (SEM), and nitrogen sorption porosimetry. Complementary X-ray computed microtomography $(\mu \mathrm{CT})$ and synchrotron $\mu \mathrm{CT}$ analysis were also performed to investigate the 3-D microstructure and pore morphology of the biporous networks. Finally, swelling behavior of those materials was investigated so as to understand the contribution of each porosity level and the impact of interconnection in the higher porosity level.

\section{Materials and methods}

\section{Materials}

2-Hydroxyethyl methacrylate (HEMA, $97 \%$ ), ethylene glycol dimethacrylate (EGDMA, 98 $\%$ ), and 2,2-dimethoxy-2-phenylacetophenone (DMPA, $99 \%$ ) were purchased from Aldrich. Propan-2-ol ( $i$-PrOH, for analysis ACS-Reag. Ph. Eur) was supplied by Carlo Erba. Sodium chloride $(\mathrm{NaCl})$ particles with size ranging from 50 to $500 \mu \mathrm{m}$ were purchased from Prolabo; they were then sieved to isolate the particle fractions with sizes ranging from 125 to $200 \mu \mathrm{m}$, from 200 to $250 \mu \mathrm{m}$, and from 250 to $400 \mu \mathrm{m}$ that were stored in moisture-free conditions. All reagents and solvents were used without any further purification procedure.

\section{Preparation of doubly porous PHEMA-based materials}

Firstly, fractions of $125-200 \mu \mathrm{m}, 200-250 \mu \mathrm{m}$ and 250-400 $\mu \mathrm{m} \mathrm{NaCl}$ particles were fused by Spark Plasma Sintering (SPS) procedure so as to obtain a 3-D NaCl particle template. A Sumitomo Dr. Sinter Lab 515S SPS machine from Fuji Electronic Industrial was used. For the sintering treatment, $2 \mathrm{~g}$ of $\mathrm{NaCl}$ particles were introduced into a cylindrical graphite die (diameter: $10 \mathrm{~mm}$ ) and heated from room temperature to $100{ }^{\circ} \mathrm{C}$ at a heating rate of $40{ }^{\circ} \mathrm{C} \mathrm{min}^{-1}$. A $3 \mathrm{kN}$ force was applied onto the sample under argon. After $5 \mathrm{~min}$ at $100{ }^{\circ} \mathrm{C}$, the fused template was cooled to room temperature at a rate of $40{ }^{\circ} \mathrm{C} \mathrm{min}^{-1}$. For the sake of comparison, 200-250 $\mu \mathrm{m}$ sieved $\mathrm{NaCl}$ particles were also used without any sintering procedure. $2 \mathrm{~g}$ of particles were weighed in a vial and then gently stirred under orbital shaker in order to ensure homogeneous 
particle packing. In a second step, HEMA and EGDMA were mixed with a molar ratio of 70/30 mol. \% in the presence of DMPA (2 wt. \% with respect to the comonomers), and propan-2-ol (80 vol. \%). The mixture was added to the $\mathrm{NaCl}$ particle template (either sintered or not), and the polymerization was conducted in a UV oven for $4 \mathrm{~h}$ at $365 \mathrm{~nm}$. Non-sintered $\mathrm{NaCl}$ particles were removed by extraction with deionized water for 3 days (water was changed once a day), while sintered $\mathrm{NaCl}$ particles were removed for one day. After this porogen extraction step, the samples were washed abundantly with water, and dried at room temperature under vacuum. The samples were analyzed by gravimetry so as to confirm the total removal of the porogenic agents ( $\mathrm{NaCl}$ macroparticles and solvent).

\section{Morphology of (bi)porous PHEMA polymers}

SEM observation of the materials was performed on a MERLIN microscope from Zeiss equipped with InLens and SE2 detectors using a low accelerating tension (2-3 kV) with a diaphragm aperture of $30 \mu \mathrm{m}$. The samples were first cryofractured and coated with a $4 \mathrm{~nm}$ layer of palladium/platinum alloy in a Cressington 208 HR sputter-coater.

\section{Determination of porous features}

Porosity ratios, pore volumes, and pore size distributions of the materials were determined by mercury intrusion porosimetry (MIP) using a Micromeritics AutoPore IV 9500 porosimeter. The determination of the porosity features was based on the Washburn equation between the applied pressure (from 1.03 to $206.8 \mathrm{MPa}$ ) and the pore size into which mercury intruded. The nitrogen sorption measurements were carried out at $77 \mathrm{~K}$ with a Quantachrome Autosorb iQ analyzer. The specific surface area values for the investigated porous polymers were quantified using the BET method at relative pressure $\left(P / P_{0}\right)$ values ranging from 0.05 to 0.3 .

\section{Study of the microstructure of (bi)porous scaffolds by X-Ray microtomography}

The computed X-ray microtomography investigations were performed using an Ultratom microtomograph system manufactured by RX Solutions. Two imaging setups were used, providing 3-D images with different spatial resolutions. In the first one, aimed at imaging the whole manufactured samples of $1 \mathrm{~cm}$ in diameter, a Hamamatsu L10801 micro-focus reflection X-ray source (max. $230 \mathrm{kV}$ and $200 \mathrm{~W}$, min. spot size $5 \mu \mathrm{m}$ ) was combined with a Varian 2520 flat panel detector $(1920 \times 1536$ pixels, pixel size: $127 \mu \mathrm{m}$, CSI scintillator $)$. The second configuration based on a Hamamatsu nano-focus transmission L10711-23 source (max. $160 \mathrm{kV}$ and $15 \mathrm{~W}$, min. spot size $0.25 \mu \mathrm{m}$ ) and a $4008 \times 2672$ pixels VHR camera from Photonic Science (pixel size $9 \mu \mathrm{m}$, Gadox scintillator) was used to investigate smaller samples at a higher resolution. 3-D images were reconstructed from the radiographic projections using the $\mathrm{X}$-act software provided by the manufacturer. For the larger scale investigations, the experimental 
protocol consisted in sticking a cylindrical biporous PHEMA sample, about $1 \mathrm{~cm}$ in diameter, on top of a thin cylindrical holder, which was mounted on the rotating stage of the microtomograph. The micro-focus source was set at $25 \mathrm{kV}$ tension and $400 \mu \mathrm{A}$ intensity, and the geometric setup ensured a voxel size of $8.75 \mu \mathrm{m}$ in the reconstructed images. 1440 radiographic projections were taken over a complete 360-degree rotation in about $10 \mathrm{~h}$, and 3D images of $1840 \times 1840 \times 1270$ voxels were reconstructed. For the smaller scale investigation, the sample of about $3 \mathrm{~mm}$ in diameter was held in a plastic straw, which was stuck on the rotating stage. The nano-focus source was used at $50 \mathrm{kV}$ tension and $100 \mu \mathrm{A}$ beam intensity. The camera was used in $4 \times 4$ binning mode in order to increase the signal to noise ratio. The 700 projections were recorded in about $2 \mathrm{~h}$ and the 3-D reconstructed images had a definition of $1000 \times 1000 \times 700$ voxels, with a voxel size of $2.0 \mu \mathrm{m}$; scanning time was about $2 \mathrm{~h}$. All the images shown in this study were analyzed with the Fiji ${ }^{\circledR}$ Freeware. As the considered materials were almost transparent to X-rays, the obtained images were rather noisy. That is the reason why they had to be digitally filtered for some investigations; the "2-D anisotropic diffusion" filter available in Fiji has been selected to process the 2-D slices, for its ability to reduce noise while preserving interfaces.

\section{Synchrotron X-ray tomography imaging}

The synchrotron X-ray tomography investigations were performed at Synchrotron Soleil (Saint Aubin, France) on the ANATOMIX beamline with a parallel beam and a pink beam with an energy range from 5 to $25 \mathrm{keV}$, resulting from the use of a $12.5 \mathrm{~mm}$ gap on the ondulator and filtering by $\mathrm{Au}$. Note that the Anatomix beamline is the latest beamline of Synchrotron, constructed in the context of the EquipEx project NanoImagesX. Our experiment run in April 2018 was the first official user-experiment on this line, which was still in a temporary, not optimized, configuration. A local tomography was performed with a $10 \times$ optics in absorption contrast mode and a Hammamatsu Orca Flash 4.0 V2 camera $(2048 \times 2048$ pixels, $6.5 \mu \mathrm{m})$, associated with a scintillator $500 \mu \mathrm{m}$ in thickness. The cylindrical material of about $1 \mathrm{~cm}$ in diameter was stuck on a PMMA sample holder inserted on the rotating stage. Radiographic scans using 2000 to 8000 projections were run together with the acquisition of "dark" (i.e. without beam) and "at" images (i.e. without sample), averaged over 50 frames. Because the setup was not yet optimized, only the central part of the radiographs were perfectly focused, on a height of about 1000 pixels. During these experiments, 2 acquisition modes were carried out. In the first one, the sample is scanned over $180^{\circ}$ (4 times) to reconstruct an image of $2000 \times$ 2000 pixels with low noise. The second one is a $360^{\circ}$ scan with an off-center axis and 2 heights, to reconstruct 2 juxtaposed images of $4000 \times 4000 \times 2000$ pixels with an overlap. 


\section{Water uptake determination}

In a typical experiment, a known weight $\left(\mathrm{W}_{\mathrm{d}}\right)$ of PHEMA (bi)porous polymer was immersed in milliQ deionized water. At specific times, the same sample was weighted to obtain $\mathrm{W}_{\mathrm{w}}$ as a function of time. The water uptake of the polymer networks can be expressed following Eq. (1):

Water Uptake $=\frac{W_{w}-W_{d}}{W_{d}} \quad$ Equation 1

where $\mathrm{W}_{\mathrm{w}}$ and $\mathrm{W}_{\mathrm{d}}$ stand for the wet mass and the dry mass, respectively. The monitoring of water uptake as a function of time was stopped when a plateau was reached.

\section{Results and discussion}

As previously demonstrated in different studies, $\mathrm{NaCl}$ particles have been successfully used to generate macroporous [21] or biporous materials through particle templating combined to a porogenic solvent after a straightforward porogen removal [22-24]. It should be stressed that previous reports based on the double porogen approach using $\mathrm{NaCl}$ as a macroporogen only concerned either non-sintered $\mathrm{NaCl}$ particles [16] or sintered ones [23, 24], and no thorough investigation of the influence of nanoporogen or even macroporogen features on pore morphology was provided. Recently, we have developed a somehow smarter strategy toward doubly porous PHEMA-based networks in which $\mathrm{NaCl}$ macroparticles sintered through the SPS technique are used to form a 3-D continuous macroporogenic template in conjunction with a porogenic agent consisting of a suitable solvent. In one such case, the 3-D continuous $\mathrm{NaCl}$ particle-based template leads to a macroporosity level, while the porogenic solvent ensures a lower porosity level through a phase separation process during the polymerization step [18-20]. At this stage, it is worth mentioning that the porogenic solvent must obviously be miscible with the comonomers in order for the phase separation to occur during the copolymerization process. Indeed, when the polymerization is at an advanced step, the incompatibility between the solvent and the polymeric network results in the expulsion of solvent molecules from the polymer, thus leading to pores whose sizes depend notably on the nature and concentration of the solvent as well as the crosslinker concentration [19]. The advantage of our approach, that is based on the concomitant use of two distinct porogenic agents, namely $\mathrm{NaCl}$ macroparticles and a porogenic solvent ( $i-\mathrm{PrOH}$ in the present study), lies in the independent control of each porosity level. In 
our previous studies [19], we have thus shown that the use of more and more hydrophobic alcohols as porogens for the preparation of hydrophilic PHEMA-based crosslinked materials leads to increasing average pore sizes for the lower porosity level without any significant modification of the macroporosity. Likewise, an increasing proportion of the porogenic solvent also leads to increasing pore sizes related to the lower porosity level, while decreasing the upper to lower porosity ratio.

\section{Effect of macroporogen packing on doubly porous materials}

The present study is specifically focused on the macroporogen packing effect on biporous PHEMA-based networks by comparing sintered $v$ s. non-sintered $\mathrm{NaCl}$ macroparticles with a size range comprised between 200 and $250 \mu \mathrm{m}$. The polymerization mixture was constituted of a fixed HEMA/EGDMA molar ratio of $70 / 30 \mathrm{~mol}$. \% in conjunction with $80 \mathrm{vol}$. $\%$-PrOH with respect to the comonomer volume. The MIP profiles and SEM micrographs of the resulting doubly porous PHEMA-based materials are respectively reported in Fig. 1 and Fig. 2, while their main porous features are gathered in Table 1. The biporous structure prepared from nonsintered $\mathrm{NaCl}$ particles (Fig. 1a) exhibited an ill-defined dual porosity along with pore sizes with a macroporosity centered around $200 \mu \mathrm{m}$ and a lower porosity level centered around $6 \mu \mathrm{m}$. In sharp contrast, doubly porous networks prepared from SPS-sintered $\mathrm{NaCl}$ particles presented a well-defined bimodal porosity with a first macropore size of about $60 \mu \mathrm{m}$ and a second macropore size around $1.5 \mu \mathrm{m}$, as observed in Fig. $\mathbf{1 b}$.
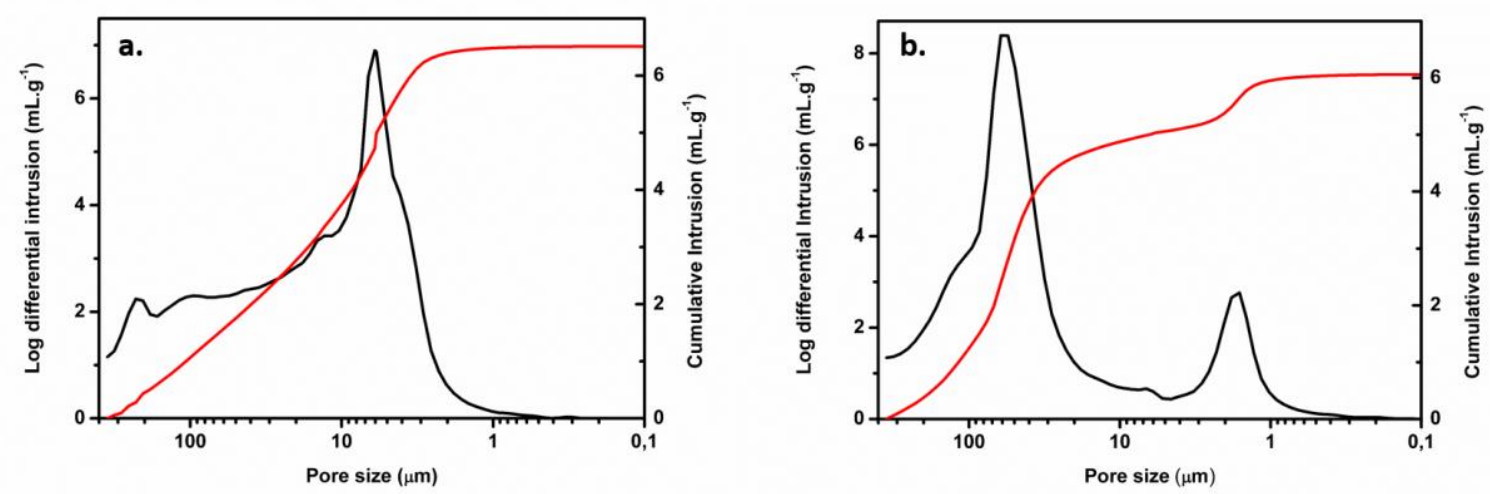

Fig. 1 MIP profiles of biporous PHEMA materials prepared from 200-250 $\mu \mathrm{m}$ non-sintered (a) or SPS-sintered (b) $\mathrm{NaCl}$ particles. 
Table 1 Porous features of biporous PHEMA-based materials with non-interconnected and interconnected macropores.

\begin{tabular}{|c|c|c|}
\hline Porous characteristics & $\begin{array}{c}\text { Non-interconnected } \\
\text { macropores }\end{array}$ & $\begin{array}{c}\text { Interconnected } \\
\text { macropores }\end{array}$ \\
\hline Larger macropore size $(\mu \mathrm{m})^{\mathrm{a}}$ & 200 & 60 \\
\hline Smaller macropore size $(\mu \mathrm{m})^{\mathrm{a}}$ & 6 & 1.5 \\
\hline Upper to lower porosity ratio (vol. \%) & $\mathrm{nd}^{\mathrm{c}}$ & $80 / 20$ \\
\hline Total pore volume $\left(\mathrm{mL} \mathrm{g}^{-1}\right)^{\mathrm{a}}$ & 6.5 & 6.0 \\
\hline Porosity ratio $(\%)^{\mathrm{a}}$ & 80 & 87 \\
\hline Specific surface area $\left(\mathrm{m}^{2} \mathrm{~g}^{-1}\right)^{\mathrm{b}}$ & 80 & 105 \\
\hline
\end{tabular}

${ }^{a}$ Values as determined by MIP.

${ }^{\mathrm{b}}$ Values as determined by nitrogen sorption measurements (BET method).

${ }^{\mathrm{c}}$ This ratio could not be determined properly.
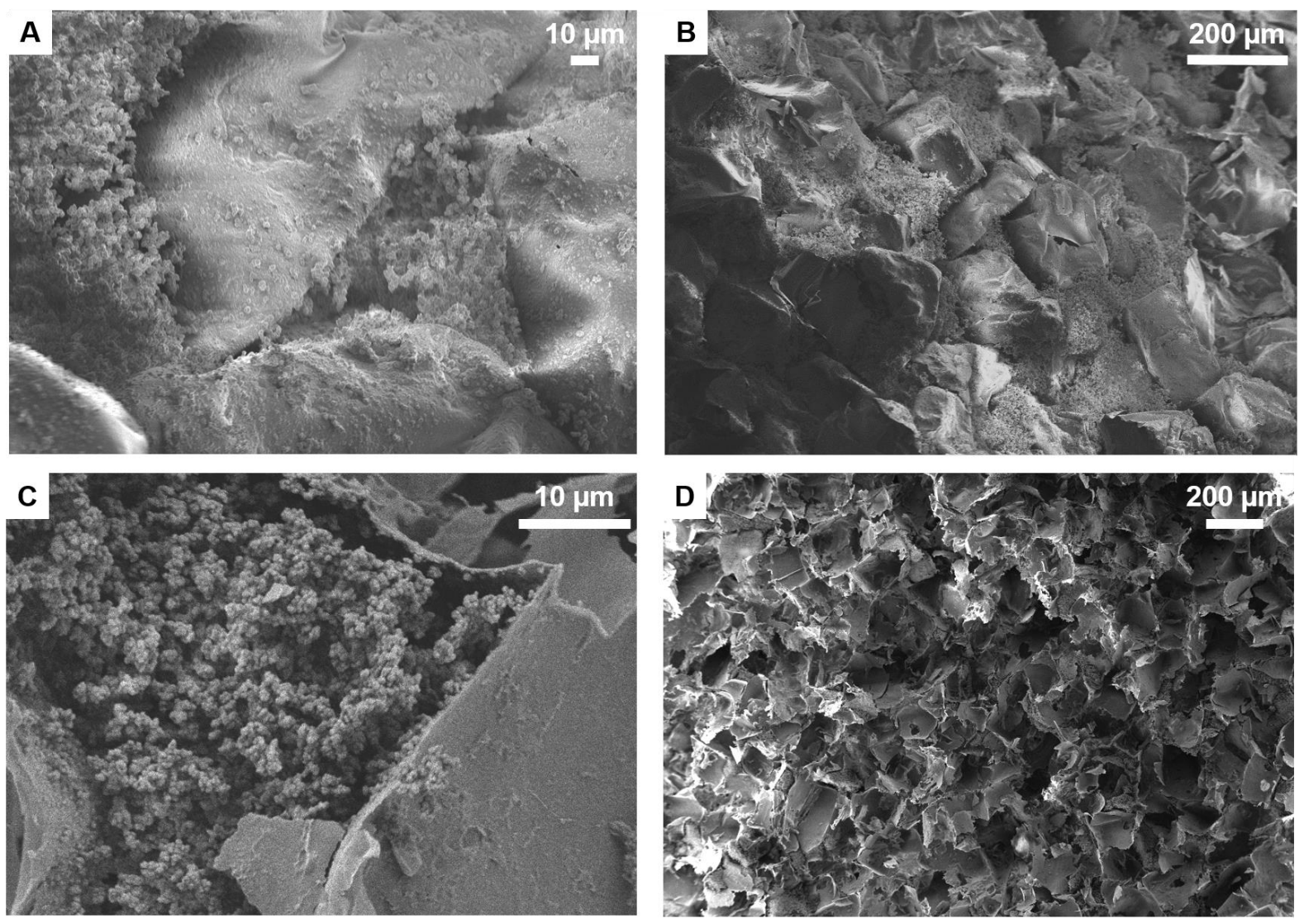

Fig. 2 SEM micrographs of biporous PHEMA-based materials with non-interconnected macropores prepared by using non-sintered $\mathrm{NaCl}$ particles $(\mathrm{A}, \mathrm{B})$ and with interconnected macropores prepared by using SPS-sintered $\mathrm{NaCl}$ particles $(\mathrm{C}, \mathrm{D})$. 
It is worth mentioning that the pore sizes obtained from MIP measurements are often underestimated when compared to SEM observations. This has already been observed notably with poly(HIPE) samples [25] or when using fused PMMA beads as macroporogens [20], and it could be explained by the threshold size theory that was reported in the literature concerning MIP measurements on cement-based materials [26]. This original biporous material presented a upper to lower porosity volume ratio equal to $80 / 20 \mathrm{vol}$. \%. In this case, the resulting biporous material presented interconnected macropores and thus a higher porosity ratio, i.e. $87 \%$ compared to $80 \%$ for the corresponding analogue prepared from non-sintered $\mathrm{NaCl}$ particles, due to closer particle packing resulting from SPS-mediated $\mathrm{NaCl}$ sintering. As it can be seen in Fig. 2, SEM observations of the biporous material prepared from non-sintered macroporogenic agent clearly showed the occurrence of two porosity levels. Non-interconnected macropores having $\mathrm{NaCl}$ particle imprints could be detected (Fig. 2B), while globular polymeric structures were observed within the macropore walls delimiting an interconnected network with a lower porosity level (Fig. 2A), that is usually found when phase separation occurs in such polymerization mixtures constituted of at least one porogenic solvent. In the latter case, the interconnection between adjacent macropores appeared to be largely absent. Comparatively, SEM investigation of the biporous PHEMA framework obtained from sintered $\mathrm{NaCl}$ particles showed a high level of interconnections between adjacent macropores, while each level of porosity was preserved. One such sample exhibited a higher specific surface area, i.e. $S_{\mathrm{BET}}=$ $105 \mathrm{~m}^{2} \mathrm{~g}^{-1}$, than that with non-interconnected macropores $\left(S_{\mathrm{BET}}=80 \mathrm{~m}^{2} \mathrm{~g}^{-1}\right)$, as measured from nitrogen sorption porosimetry.

$\mu \mathrm{CT}$ has recently been implemented for the characterization of macroporous polymer-based materials, and especially for biodegradable porous polymers dedicated to tissue engineering applications [27-32]. This remarkable technique notably allowed for some 3-D volumic rendering of the porous materials or the corresponding macroporogenic templates [30], thus leading to significant information that could be complementary to more classical SEM and MIP techniques. A significant advantage of $\mu \mathrm{CT}$ with respect to SEM was its ability to investigate the bulk of the material in a non-destructive manner, with almost no constraints in terms of sample preparation. Unlike MIP, it provided also a direct, at least qualitative, information on pore size and geometry. On the other hand, spatial resolution of $\mu \mathrm{CT}$ was still limited and the low X-ray absorption contrast provided by highly porous polymeric materials led to noisy images.

$\mu \mathrm{CT}$ imaging was first performed on doubly porous PHEMA cylindrical samples $1 \mathrm{~cm}$ in diameter, and in this particular case, the $\mathrm{NaCl}$ macroporogens were not previously sieved (grain 
size between 50 and $500 \mu \mathrm{m}$ ). The microstructure of samples elaborated from non-sintered (Fig. 3a) and SPS-sintered (Fig. 3b) $\mathrm{NaCl}$ particles permitted to confirm the surface observations made by SEM regarding the macroporous network (i.e. upper porosity level). As shown in Fig. 3, the pore distribution was rather homogeneous in both samples, and they showed a macroporous network with pore imprints of sizes similar to those of $\mathrm{NaCl}$ particles. The exploration of the 3-D image of the sample prepared from non-sintered $\mathrm{NaCl}$ (cross-section presented in Fig. 3a) qualitatively confirmed that the macropores were mostly isolated within the polymer matrix. The macropore morphology presented various shapes, such as pseudocubes, spheres, and pyramids. The matrix exhibited some large areas without pores, a few hundred micrometers in size; some thin matrix walls separating pores, or even inside pores, with a thickness close to voxel size, could however also be observed. A few neighbor pores seemed to be connected; it was however not clear whether they were separated or not by a thin matrix wall which could not be resolved by the 3-D image of the whole samples. Such situations were however seldom.

The 3-D $\mu \mathrm{CT}$ image of the sample obtained from the SPS-fused particles, a cross-section of which was provided in Fig. 3b, showed a microstructure with mostly pseudo-spherical pores separated by much regular and thinner matrix walls (less than $50 \mu \mathrm{m}$ ). However, the 3-D exploration of these data showed that most pores seemed to be connected to their neighbors. Similar connections could be found for almost all pores in other cross-sections. Strictly speaking, this did not prove that pores were really connected, as separating walls could have been too thin with respect to image resolution. These observations were however consistent with the expected features of the microstructure of this material. It is noteworthy that some bright area could be observed on the periphery of the sample reflecting strongly attenuating constituents, which might be residual $\mathrm{NaCl}$ particles potentially entrapped in the material and not removed during preparation. 

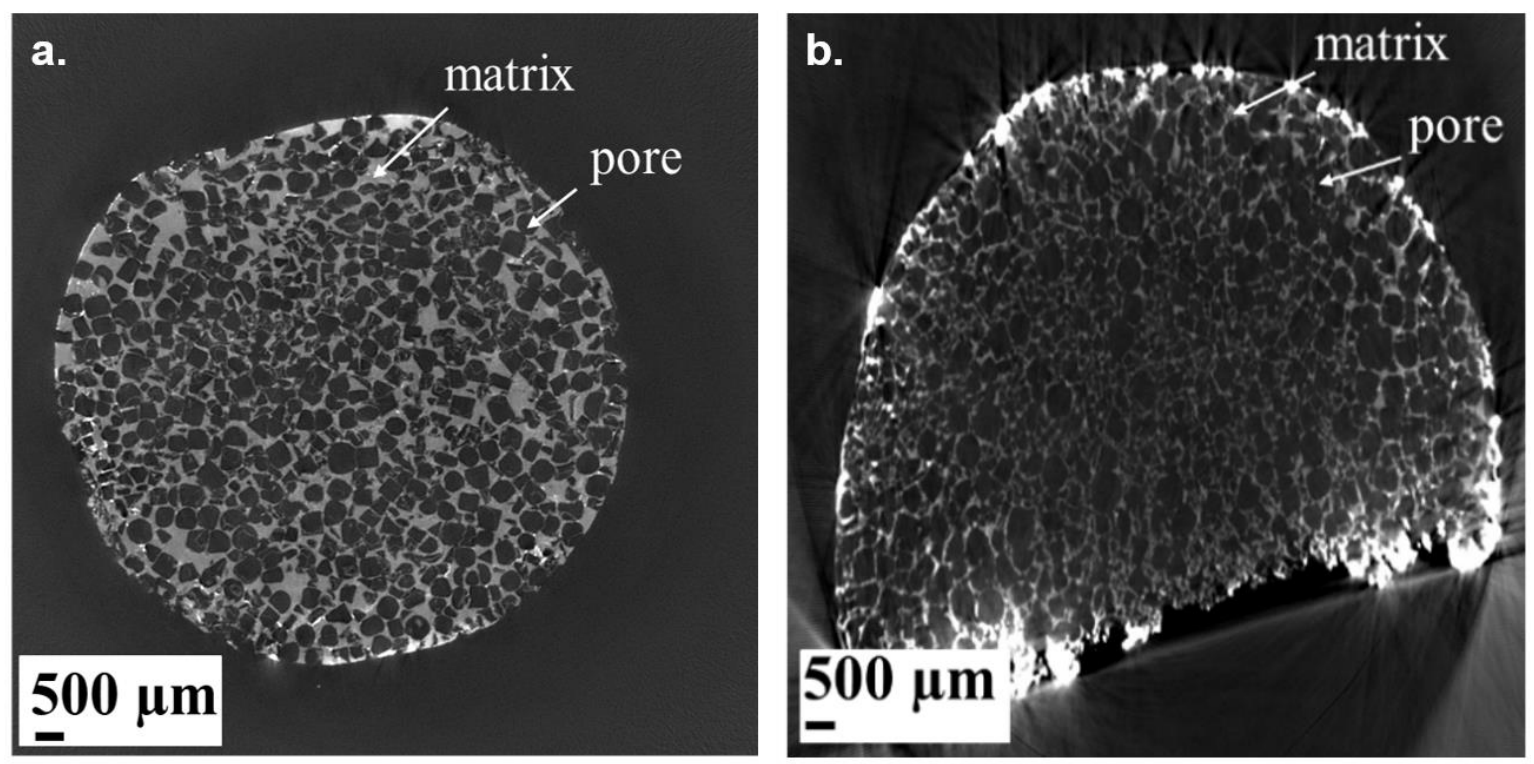

Fig. $3 \mu \mathrm{CT}$ pictures of porous PHEMA-based networks exhibiting non-interconnected macropores (a) and interconnected macropores (b).

The major differences between both samples, as qualitatively demonstrated by the $\mu \mathrm{Ct}$ images, laid in the interconnection between adjacent macropores, the pore shape and the matrix volume fraction. It is noteworthy that the polymer matrix proportion was obviously more important for the material displaying non-interconnected macropores. This could be explained as the consequence of the random packing of inorganic macroporogens used in the preparation of the $\mathrm{NaCl}$ template associated with the porous materials. This result was also confirmed more quantitatively by experimental measurements of the density of samples elaborated from nonsintered $\mathrm{NaCl}$ particles which was equal to $0.093 \mathrm{~g} . \mathrm{cm}^{-3}$ while materials prepared with SPSsintered $\mathrm{NaCl}$ particles showed a $0.067 \mathrm{~g} . \mathrm{cm}^{-3}$ density. Such a global measurement of density allows one to directly compare the macroporosity, if one assumes the lower porosity level to be the same in both samples, which sounds reasonable in a first approximation as both pore forming mechanisms are essentially independent.

Furthermore, the macroporosity of the sample obtained from non-sintered $\mathrm{NaCl}$ was quantitatively evaluated from its $\mu \mathrm{CT}$ image with the following methodology. The average grey level $\mathrm{g}_{\mathrm{av}}$ of a large region of interest of the sample, made of 200 slices, was compared to the average grey level of voids $g_{v}$, and of microporous matrix $g_{m}$, which could be determined by a manual selection within a 2-D cross section of sufficiently large domains strictly included in the pore or matrix phase. As grey levels in $\mu \mathrm{CT}$ images reflect average $\mathrm{X}$-ray attenuation coefficients, which in case of two-phase materials are essentially proportional to the volume 
fraction of constituents within voxels, a simple rule of mixture can be used to evaluate the average macroporosity $P$ from these quantities, [33] according to $\mathrm{g}_{\mathrm{av}}=P \times \mathrm{g}_{\mathrm{v}}+(1-P) \times \mathrm{g}_{\mathrm{m}}$. When applied to non-filtered images (see Fig $4 \mathbf{4}$ for a typical cross- section), this procedure led to an evaluation of $P$ of $64 \%$.

A similar procedure could however not be applied efficiently to the other sample obtained from fused $\mathrm{NaCl}$ because the value of $\mathrm{g}_{\mathrm{m}}$ was difficult to quantify precisely, for two reasons (see Fig. 4d): first, the matrix domains are much thinner so that it is hard to select large domains made of matrix only, and second, the grey levels within the matrix exhibited larger fluctuations, possibly because of a larger variability of the lower porosity level, or the presence of residual traces of $\mathrm{NaCl}$ (as observed near the periphery of the sample). However, assuming a similar lower porosity level in both samples, the macroporosity of the second material could be deduced from that of the first one and from the ratios of the overall densities. In this way, a macroporosity of $74 \%$ was found for SPS-sintered samples, i.e. a value very close to that found independently by means of MIP, which is $0.8 \times 0.87=70 \%$.

Let us finally stress that a more conventional approach to evaluate volume fractions would have been based on a segmentation of images. It would however have been much less accurate and possibly biased, because of the high noise level of the images and the voxel size which is too large with respect to many small features of the microstructure, such as wall thicknesses. To illustrate this, a filtered region of interest made of 200 slices (see Fig. $\mathbf{4 b}$ for a representation of one of these) has been segmented making use of a threshold chosen such that the pore phase, defined as the voxels with a grey level below this value, represent $64 \%$ of all voxels. The resulting image is illustrated in Fig. 4c which shows significant differences with Fig. 4a, especially regarding the polymer walls. This holds for images of the material obtained from non-sintered $\mathrm{NaCl}$ grains; the situation is even more critical for the other one, for which conventional thresholding would lead to meaningless results. 

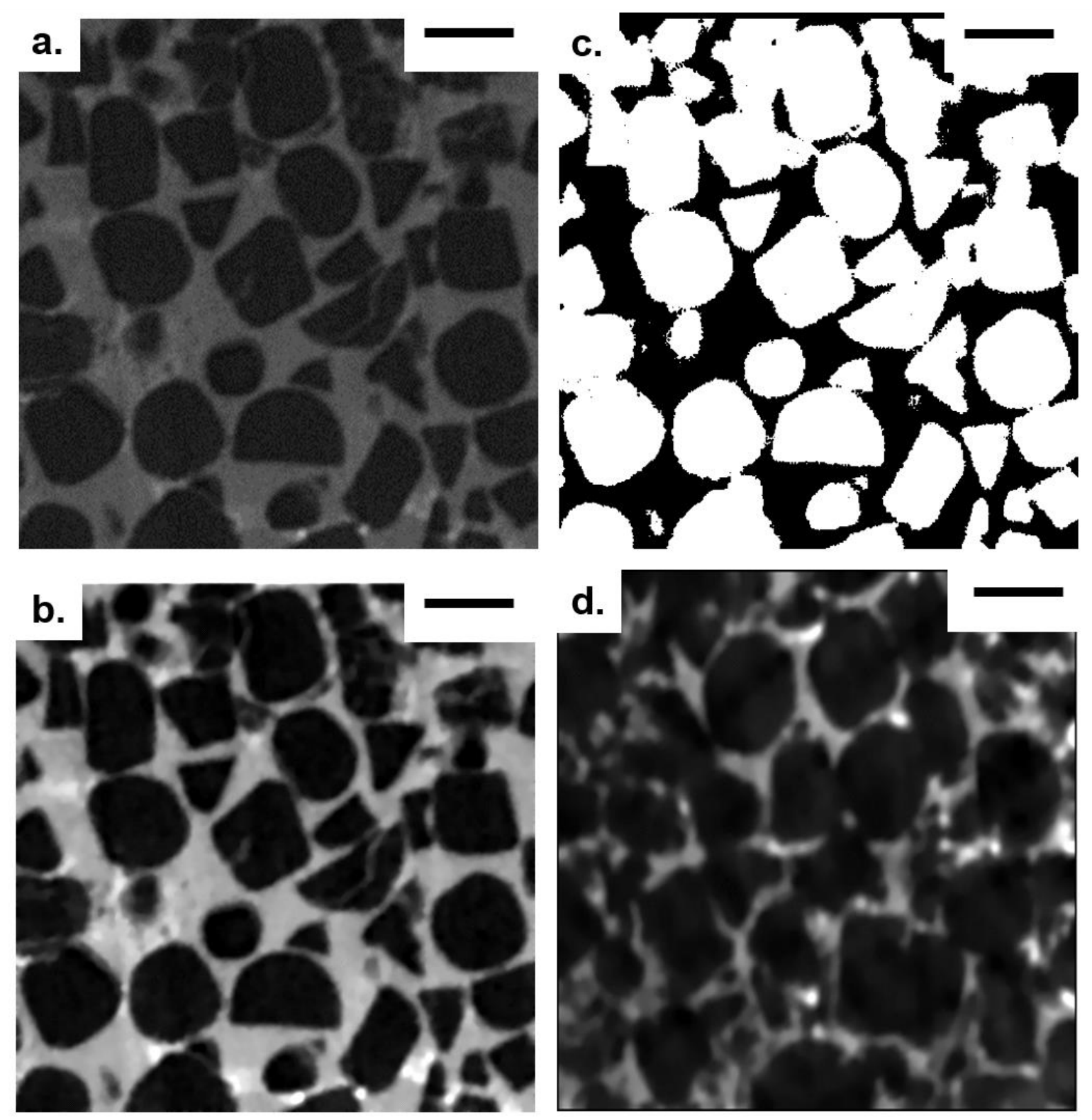

Fig. $4 \mu \mathrm{CT}$ enlarged pictures of porous PHEMA-based frameworks: (i) exhibiting non interconnected macropores before (a) and after image processing (b) as well as corresponding area after segmentation (c) or (ii) exhibiting interconnected macropores (d). Scale bars represent $500 \mu \mathrm{m}$.

\section{Effect of macroporogen size on doubly porous materials}

Further, the macroporosity of biporous PHEMA-based samples was carefully investigated by varying the size of $\mathrm{NaCl}$ particles used to generate the 3-D inorganic template of the porous materials. The choice of the macroporogen size had no significant influence on the lower porosity level as the two pore-forming mechanisms are independent, as mentioned above. The amount of porogenic solvent was kept constant, while three different fractions of sieved $\mathrm{NaCl}$ 
particles, i.e. $125-200 \mu \mathrm{m}, 200-250 \mu \mathrm{m}$, and $250-400 \mu \mathrm{m}$, were used to prepare biporous PHEMA-based materials that were then characterized finely in terms of porosity features.

MIP profiles reported in Fig. 5 logically showed a correlation between an increase in the macroporogen size and an increase in the size of resulting macropores and pore volumes. For the lowest $\mathrm{NaCl}$ size (i.e., 125-200 $\mu \mathrm{m}$ ), a macroporosity centered on $40 \mu \mathrm{m}$ was observed with a $77 \%$ porosity ratio. For the intermediate particle size (i.e., 200-250 $\mu \mathrm{m})$, the macropore size was nearly centered on $60 \mu \mathrm{m}$ with an $87 \%$ porosity ratio. Finally, biporous materials designed with the highest macroporogen size (i.e., 250-400 $\mu \mathrm{m}$ ) exhibited a macropore size of about 70 $\mu \mathrm{m}$ and a porosity ratio equal to $88 \%$. Again, it is noteworthy that the macroporogen size was higher than the corresponding macropore size. This is actually quite often observed with porous materials for which the pore size determined by MIP is generally underestimated when compared to SEM observation, likely due to the threshold size theory [25, 26]. Likewise, specific surface area values increased gradually with increasing macroporogen sizes, while the upper to lower porosity volume ratio was nearly constant (Table 2).

a.

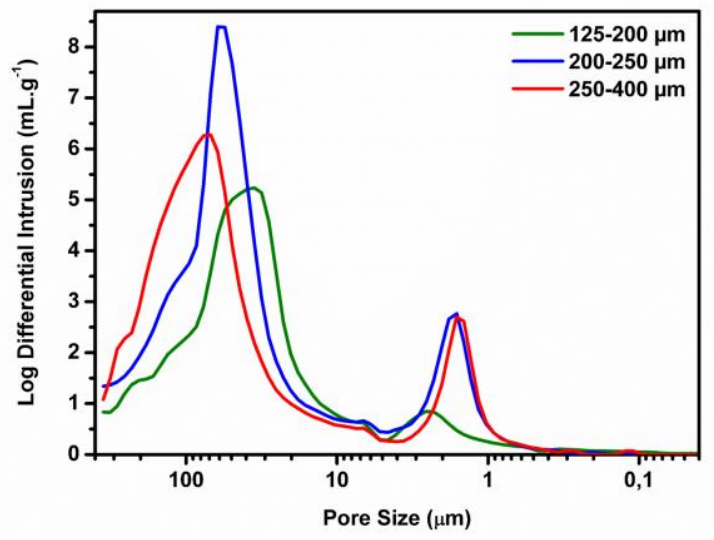

b.

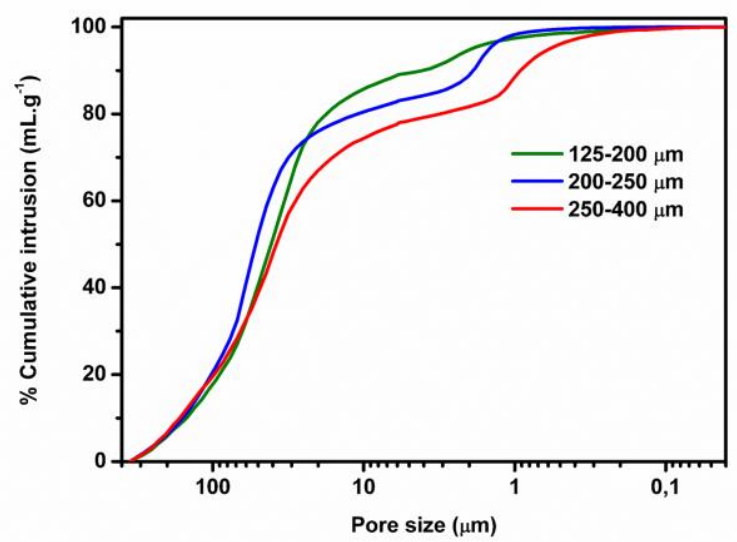

Fig. 5 (a) MIP pore size distribution profiles and (b) cumulative intrusion volumes of biporous PHEMA-based materials prepared from sintered $\mathrm{NaCl}$ particles in the presence of $i$-PrOH as a porogenic solvent. Three $\mathrm{NaCl}$ particle size fractions were used, i.e. $125-200 \mu \mathrm{m}, 200-250 \mu \mathrm{m}$, and $250-400 \mu \mathrm{m}$.

Table 2 Porous features of biporous PHEMA-based materials with varying interconnected macropore sizes. 


\begin{tabular}{lcclccc}
\hline $\begin{array}{l}\mathrm{NaCl} \\
\text { size } \\
(\mu \mathrm{m})\end{array}$ & $\begin{array}{l}\text { Larger } \\
\text { macropore }^{\mathrm{size}^{a}} \\
(\mu \mathrm{m})\end{array}$ & $\begin{array}{l}\text { Smaller } \\
\text { nanopore } \\
\text { size }^{a} \\
(\mu \mathrm{m})\end{array}$ & $\begin{array}{l}\text { Upper to lower } \\
\text { porosity ratio } \\
(\text { vol. } \%)\end{array}$ & $\begin{array}{l}\text { Total pore } \\
\text { volume }^{a} \\
\left(\mathrm{~mL} \mathrm{~g}^{-1}\right)\end{array}$ & $\begin{array}{l}\text { Porosity } \\
\text { ratio }^{a} \\
(\%)\end{array}$ & $\begin{array}{l}\text { Specific } \\
\text { surface area }^{b} \\
\left(\mathrm{~m}^{2} \mathrm{~g}^{-1}\right)\end{array}$ \\
\hline $125-200$ & 40 & 2.3 & $83 / 17$ & 4.5 & 77 & 95 \\
$200-250$ & 60 & 1.5 & $80 / 20$ & 6.0 & 87 & 105 \\
$250-400$ & 70 & 1.4 & $77 / 23$ & 10.7 & 88 & 177 \\
\hline
\end{tabular}

${ }^{a}$ Values as determined by MIP

${ }^{b}$ Values as determined by nitrogen sorption measurements (BET method)

Biporous networks prepared from $125-200 \mu \mathrm{m}$ and 200-250 $\mu \mathrm{m} \mathrm{NaCl}$ particles were analyzed via $\mu \mathrm{CT}$ imaging. As shown in Fig. 6 and Fig. 7, the macropore dispersion was homogeneous for both samples but some areas showed larger pores (approximate diameter: $500 \mu \mathrm{m}$ ) due to $\mathrm{NaCl}$ particles aggregation during sintering step. For both samples, porosity ratio was again difficult to estimate accurately using either of the above presented methods, because of high noise levels, low contrast difference between the polymer matrix and voids, and too coarse voxel size with respect to microstructural features.
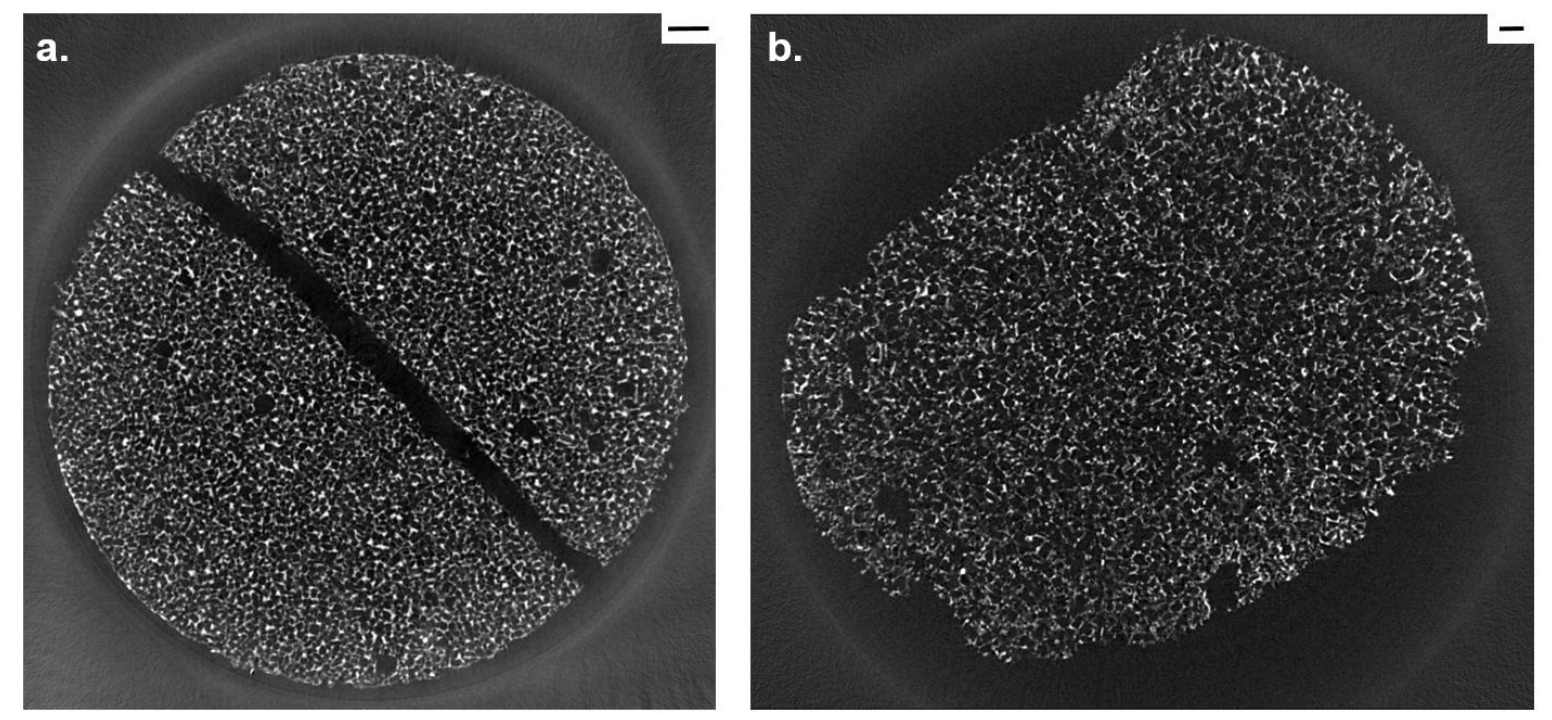

Fig. $6 \mu \mathrm{CT}$ pictures of biporous PHEMA-based networks prepared from 125-200 $\mu \mathrm{m}$ (a) and 200-250 $\mu \mathrm{m}$ (b) $\mathrm{NaCl}$ particles. Scale bars represent $500 \mu \mathrm{m}$. 

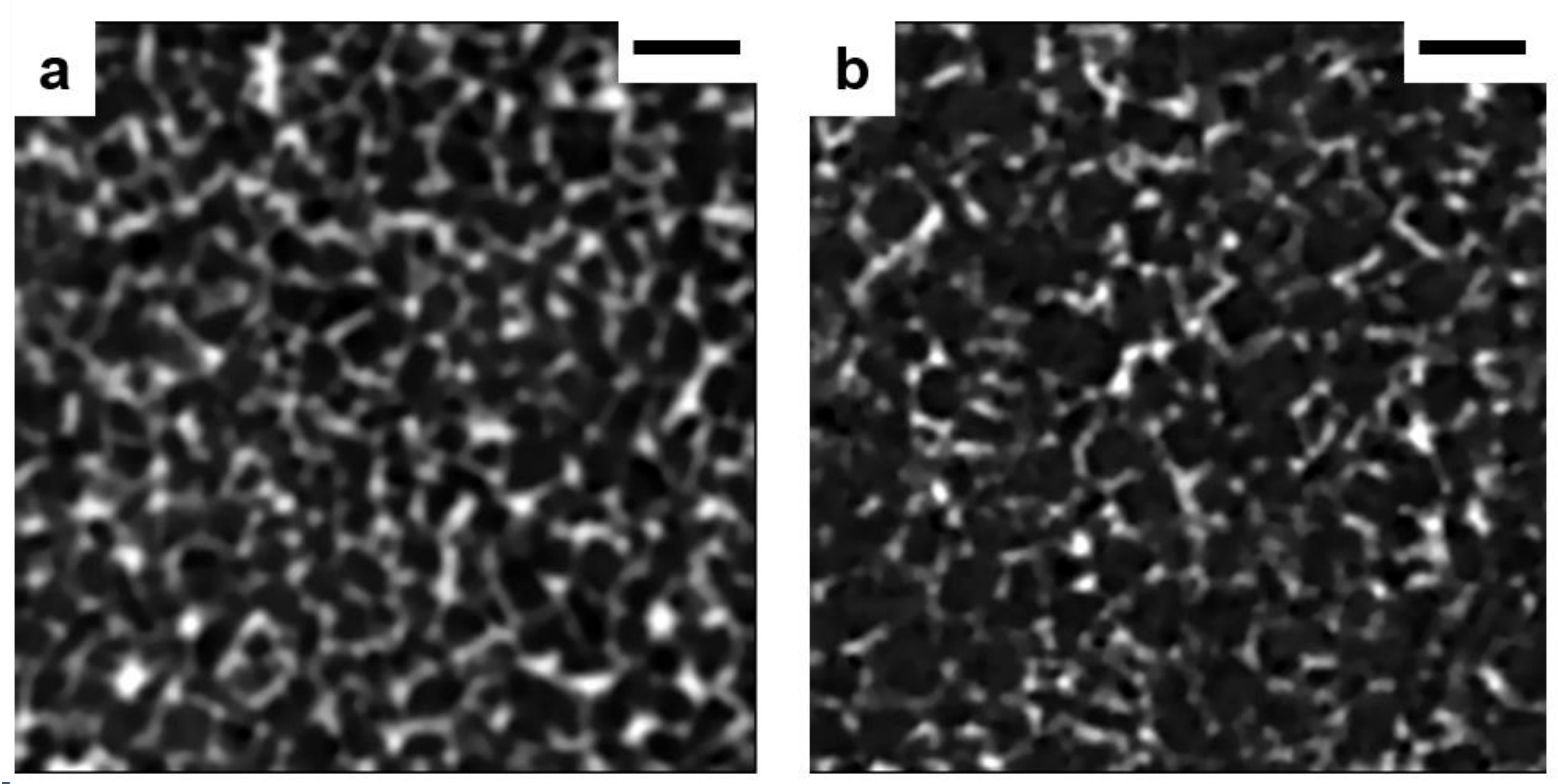

Fig. $7 \mu \mathrm{CT}$ enlarged pictures of porous PHEMA-based frameworks exhibiting interconnected macropores generated from 125-200 $\mu \mathrm{m}$ (a) and 200-250 $\mu \mathrm{m}$ (b) $\mathrm{NaCl}$ particles. Scale bars represent $500 \mu \mathrm{m}$.

In order to investigate more precisely the morphology of these materials, a sample prepared with 200-250 $\mu \mathrm{m}$ sintered $\mathrm{NaCl}$ particles was observed via $\mu \mathrm{CT}$ measurements with higher spatial resolution, namely a voxel size of $2.0 \mu \mathrm{m}$ instead of $8.75 \mu \mathrm{m}$. Despite the noise, Fig. 8 permitted to clearly observe a porous network (corresponding to the lower porosity level) within larger matrix domains, surrounded by uniform thin walls. This thickness of the latter was about 1 voxel in the images, indicating an actual physical width lower than the voxel size. This result was in good agreement with the previous SEM micrographs showing a porous structure surrounded by a homogenous polymeric shell. Furthermore, $\mu \mathrm{CT}$ image showed some isolated matrix filaments certainly formed in the thin areas near the necks between sintered grains, or in the cracks in the $\mathrm{NaCl}$ particles caused by the SPS sintering step. This very fine structure could not be resolved accurately within the images with a coarser voxel size, which explained the difficulty to segment the latter. Because of very high noise levels, it was also difficult to segment efficiently the higher resolution images. Further 3-D imaging attempts using devices with higher photon fluxes as those available on synchrotron facilities are planned in forthcoming work to investigate more quantitatively the microstructure of such materials. 


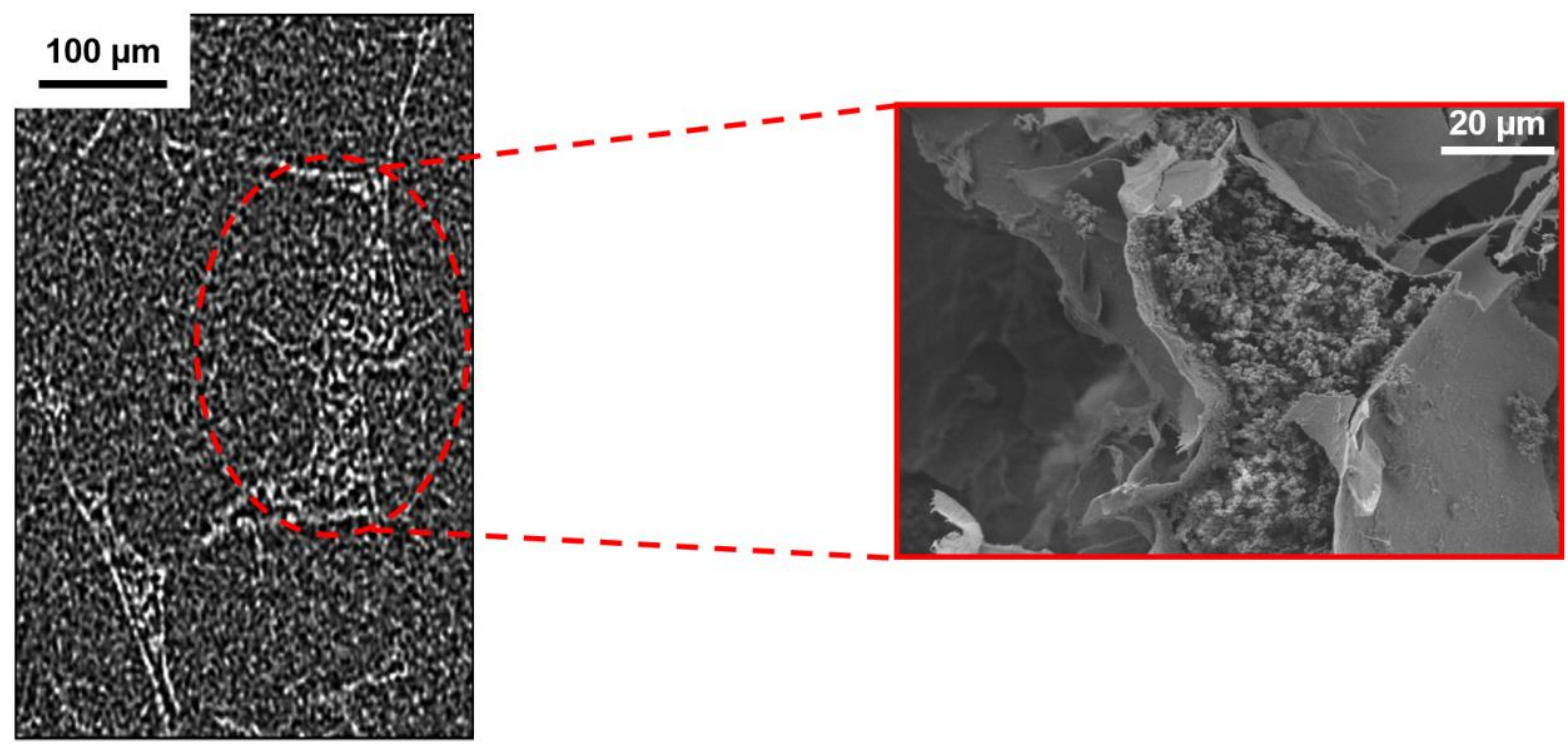

Fig. $8 \mu \mathrm{CT}$ picture and SEM micrograph of porous PHEMA-based framework exhibiting interconnected macropores generated from 200-250 $\mu \mathrm{m} \mathrm{NaCl}$ particles.

The use of synchrotron radiation as an X-ray source brought important improvements to the imaging. [34, 35] Synchrotron radiation results from the bending of a higher energy electron beam due to a magnetic field. The main advantage of this technique is that the high flux allows one to resolve very subtle variations in absorptivity and therefore in internal structure. Additional advantages of synchrotron radiation include X-ray beam collimation, which simplifies the tomographic reconstruction algorithm, and the tunability of the X-ray energy to a narrow energy band. Moreover, the use of a monochromatic X-ray beam improves the accuracy of the reconstructed tomographic images by eliminating the issue of energy dependence on X-ray absorption. In our case, synchrotron imaging is expected to provide much more accurate, less ambiguous, more spatially resolved and much less noisy images, within more reasonable scanning times. It is important to mention that the experiments were carried out on a new and not yet optimized beamline (Anatomix, Synchrotron Soleil, Saint-Aubin, France) that did not yet include a monochromator. The experiments were therefore carried out using a wide X-ray spectrum determined by the gap of the magnets and a solid filter. The spectrum was thus reduced to approximately $10 \mathrm{keV}$ providing more suitable radiation for polymer absorption compared to laboratory microtomography. Moreover, all the samples were observed directly after the elaboration without the incorporation of a contrast agent. The observation was performed on biporous samples prepared from sintered and non-sintered $\mathrm{NaCl}$ particles with sizes ranging from 125 to $400 \mu \mathrm{m}$ (Fig. 9). Monoporous materials with large interconnected and non-interconnected pores (200-250 $\mu \mathrm{m})$ were also analyzed in a second step 
(Fig. 10). X-ray synchrotron tomography permitted to considerably reduce the noise and the ring artifacts without image processing tools such as 2-D anisotropic filter. Moreover, the main advantage is that the use of a contrast agent was not necessary because the beam energy and the spatial resolution were more adapted. The reconstructed volumes were higher $\left(2000^{3}\right.$ pixels and $4000^{3}$ pixels vs. $1700^{3}$ pixels for classical microtomography) as well as the number of radiographic projections (4000/8000 vs. 1440). This technique permitted also to reduce the scanning time from $9 \mathrm{~h}$ to few minutes. As observed in the Fig. 9, the conclusions that have been made for the images obtained with classical X-ray tomography are confirmed. Indeed, three different features could be observed: the large pores, the porous polymeric matrix and the thin polymeric walls. We could notice that the interconnected materials prepared with the lowest $\mathrm{NaCl}$ particles size (i.e. 125-200 $\mu \mathrm{m}$ ) exhibited less polymeric matrix. Indeed, as the grains were smaller, these templates would have required more reactants (monomers) to form a sufficient amount of polymer which could fill all the template interstices. Furthermore, the omnipresence of the walls deformation probably induced by the drying is even more visible particularly for non-interconnected networks regardless the salt size used during the elaboration. Such observations also permitted to confirm the reliability of the use of Lugol solution, as the microstructures features are similar with and without contrast agent. 

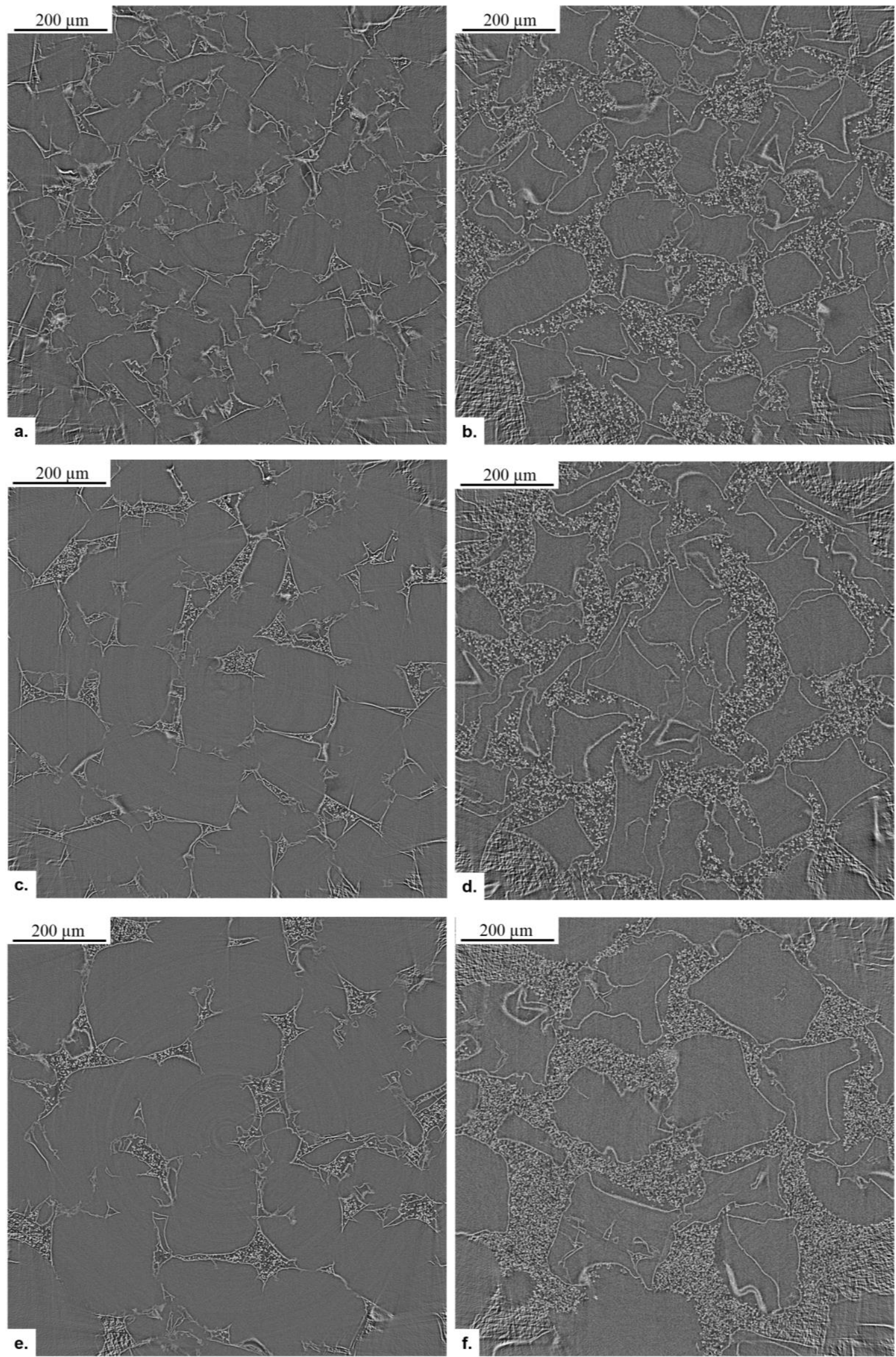

Fig. 9 Synchrotron images of doubly porous networks prepared with 125-200 $\mu$ m sintered (a) and non-sintered $\mathrm{NaCl}$ particles (b), prepared with 200-250 $\mu \mathrm{m}$ sintered (c) and non-sintered 
$\mathrm{NaCl}$ particles (d) and prepared with $250-400 \mu \mathrm{m}$ sintered (e) and non-sintered $\mathrm{NaCl}$ particles (f).

The materials exhibiting only large pores were elaborated without the use of propan-2-ol as porogenic solvent . In Fig. 10a corresponding to an interconnected network with large pores, the non-porous polymeric matrix could be observed, and the large pores size was similar to the one obtained with biporous materials (Fig. 9). In the material exhibiting non-interconnected large pores (Fig. 10b), we could observe that the $\mathrm{NaCl}$ particles were not completely extracted from the material. This is probably due to the resin that has been formed during the polymerization.
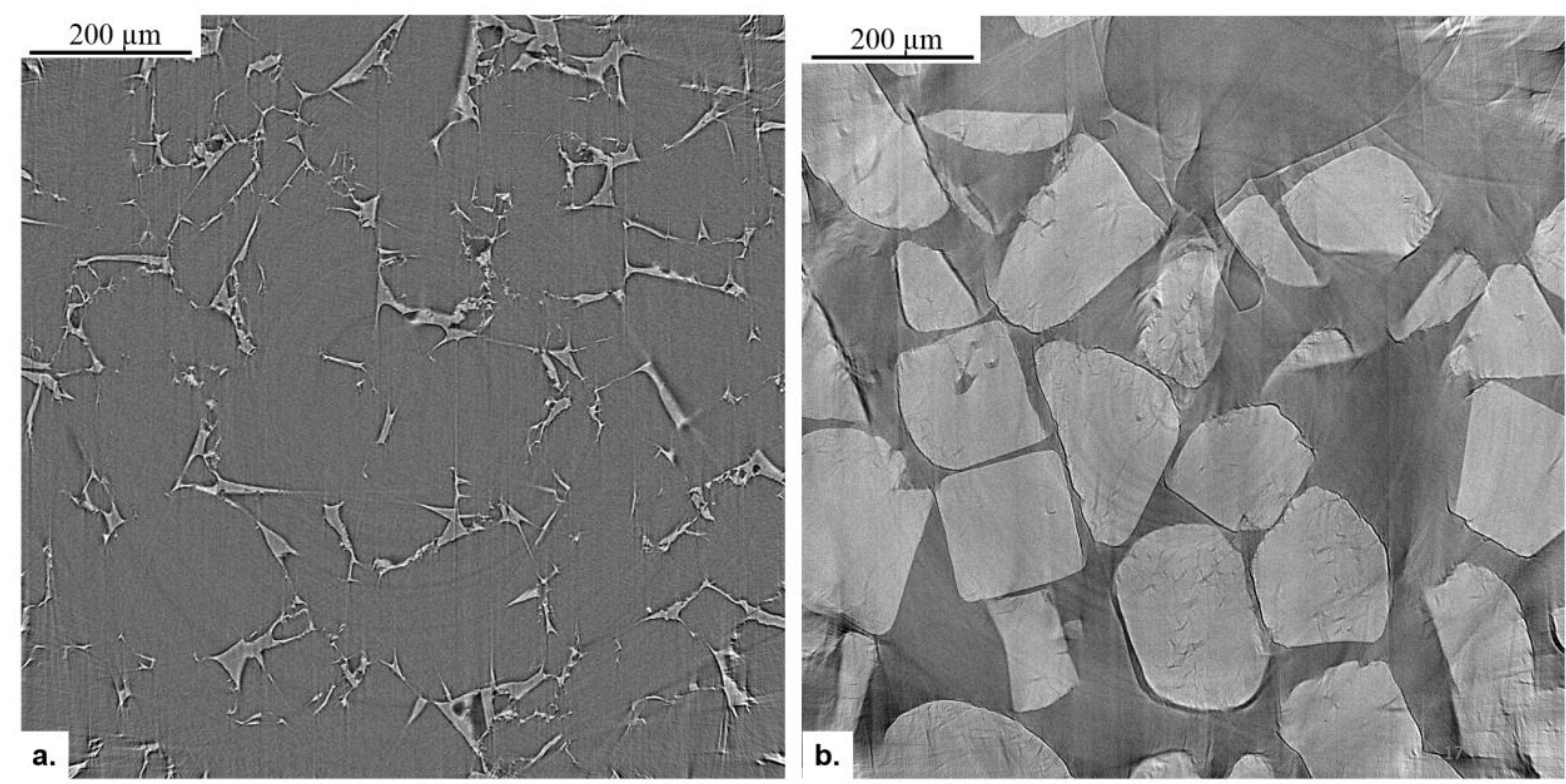

Fig. 10 Synchrotron images of monoporous networks prepared with 200-250 $\mu$ m sintered (a) and non-sintered $\mathrm{NaCl}$ particles (b).

\section{Swelling properties of mono- and biporous PHEMA-based materials}

Some of us recently demonstrated that the presence of distinct (non-)interconnected porosity levels within biporous polymeric scaffold has a crucial impact on their fluid flow transfer properties, especially on imbibition and drying. [36, 37] Several studies have also been performed regarding the swelling behavior of PHEMA-based materials in the presence of water. [38-40] For PHEMA-based biporous networks, it has been evaluated by measuring the evolution of the water uptake during $4 \mathrm{~h}$. Previously, Mabilleau et al. have notably highlighted the effect of the crosslinker backbone length on bulk PHEMA water uptake and thus swelling. [38] PHEMA crosslinked with polyethylene diacrylate exhibited the highest value of water uptake, i.e. $56 \%$, while the lowest values were obtained for divinylbenzene-crosslinked 
PHEMA and EGDMA-crosslinked PHEMA (40\% and $42 \%$, respectively). The study was performed on interconnected and non-interconnected biporous networks prepared from $\mathrm{NaCl}$ particle size between 200 and $250 \mu \mathrm{m}$. Fig. 11 represents the water uptake of interconnected and non-interconnected biporous networks as a function of time. In both cases, two plateaux were observed that probably correspond to the water filling of each porosity level. Indeed, it is likely to happen that water enters the large and small pores before binding with the polymer. In the case of interconnected networks, the water filling began with the channels between larger pores and then larger pores during $20 \mathrm{~min}$. Then, the water uptake reached a constant value equal to $1500 \%$ during $30 \mathrm{~min}$. In a second step, water drains for $1 \mathrm{~h}$ through smaller pores before reaching a second plateau. At the end of the experiment, the water uptake was approximately equal to $2400 \%$, and the mass of the wet material was almost 24 times higher than that of the dry sample. In the case of non-interconnected networks, the evolution of the swelling degree was similar excepted for the second plateau which was reached less rapidly than in the case of interconnected networks (180 min vs. $120 \mathrm{~min}$, respectively). This difference is likely due to the lack of interconnections between larger pores which should facilitate the draining of water. The water uptake was then lower in the case of non-interconnected biporous networks. Indeed, the material incorporated $1200 \%$ of water at the end of the experiment.

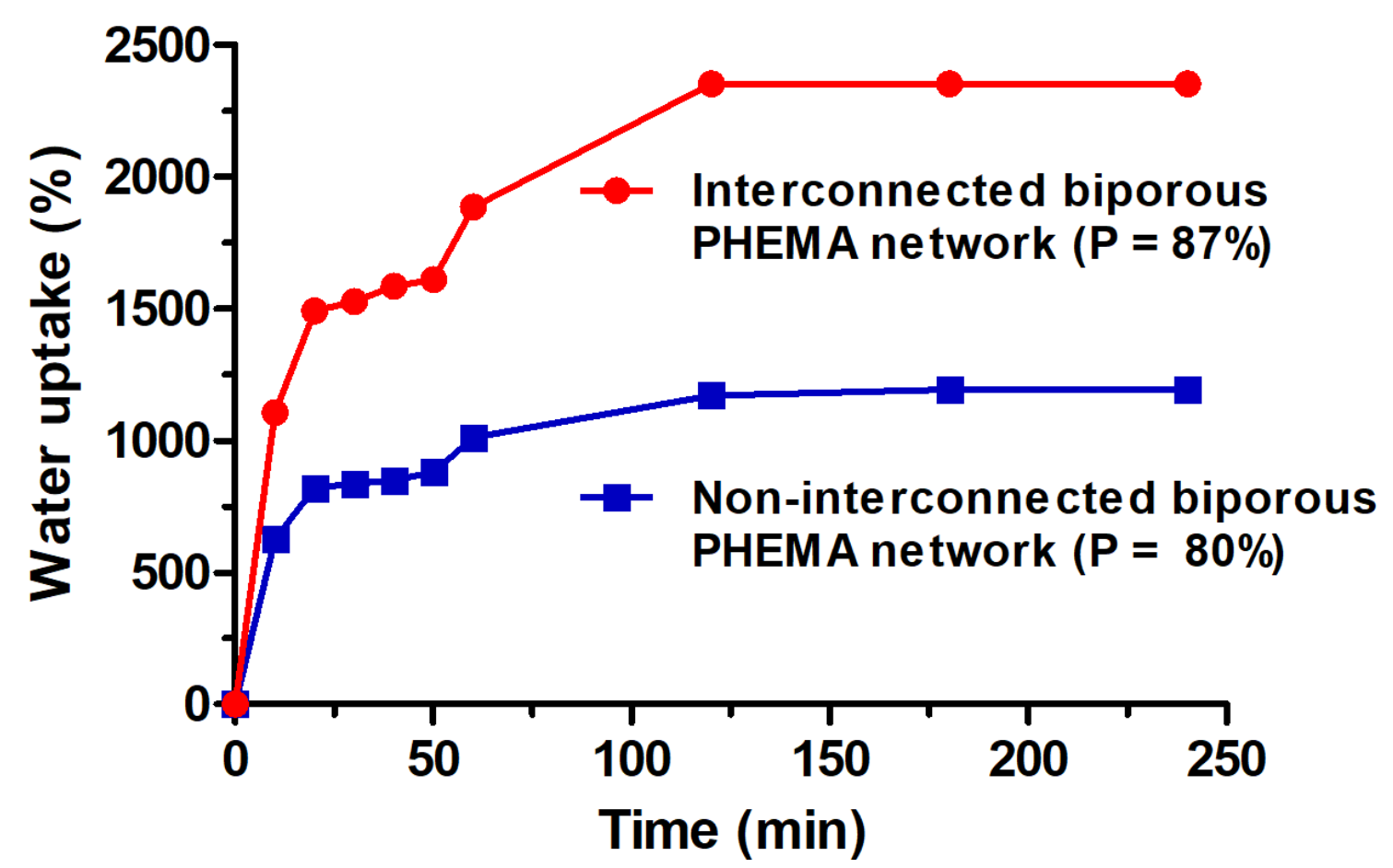

Fig. 11 Water uptake of non-interconnected and interconnected biporous networks as a function of time ( $* \mathrm{P}=$ porosity ratio). 
Water uptake was also evaluated with monoporous PHEMA-based polymers. Some previous studies showed that a bulk PHEMA-based polymer (HEMA/EGDMA, 96/4 mol. \%) incorporated $58 \%$ of water after 2 days. [38] Moreover, Lokman et. al found that PHEMA porous monoliths crosslinked with maleic anhydride and presenting $78 \%$ porosity were able to incorporate $68 \%$ of water. [40] Finally, Gomes et. al showed that the water uptake of scaffolds prepared with ethylene vinyl alcohol and cellulose acetate could reach values of around $30 \%$. [41] For the sake of comparison, we performed this study on monoporous materials exhibiting large pores or small pores. The swelling degree as a function of time is reported in Fig. 12. As expected, a monoporous network incorporated less water than a biporous one. We could notice that the equilibrium swelling degree was reached after $10 \mathrm{~min}$ in the case of a material with small pores (350\% water uptake), 40 min for a material with large interconnected pores (275 $\%$ water uptake) and 180 minutes for large non-interconnected pores (50\% water uptake). It is important to mention the presence of one single plateau in the case of monoporous samples. This observation permitted to confirm the hypothesis in which the two porosity levels were filled gradually in the case of biporous networks. In the case of materials exhibiting only small pores and samples exhibiting interconnected large pores, a constant swelling degree was reached rapidly, whereas water had more difficulties to drain through the materials with noninterconnected large pores. We could explain this phenomenon by the lack of interconnections between the larger pores. Moreover, the absence of smaller pores reduced the path of the fluid through the material. Furthermore, the thin resin formed around the material during the polymerization (due to the absence of porogenic solvent) could also slow down the passage of water. As expected, the lowest swelling degree was obtained in the case of non-interconnected monoporous network with only $50 \%$ water uptake. This observation permits to explain the low permeability of these materials and their low water uptake compared to the other structures. Finally, as expected, the swelling ratio of bulk PHEMA is very low, i.e. 6\%, when compared to its (bi)porous counterparts. 


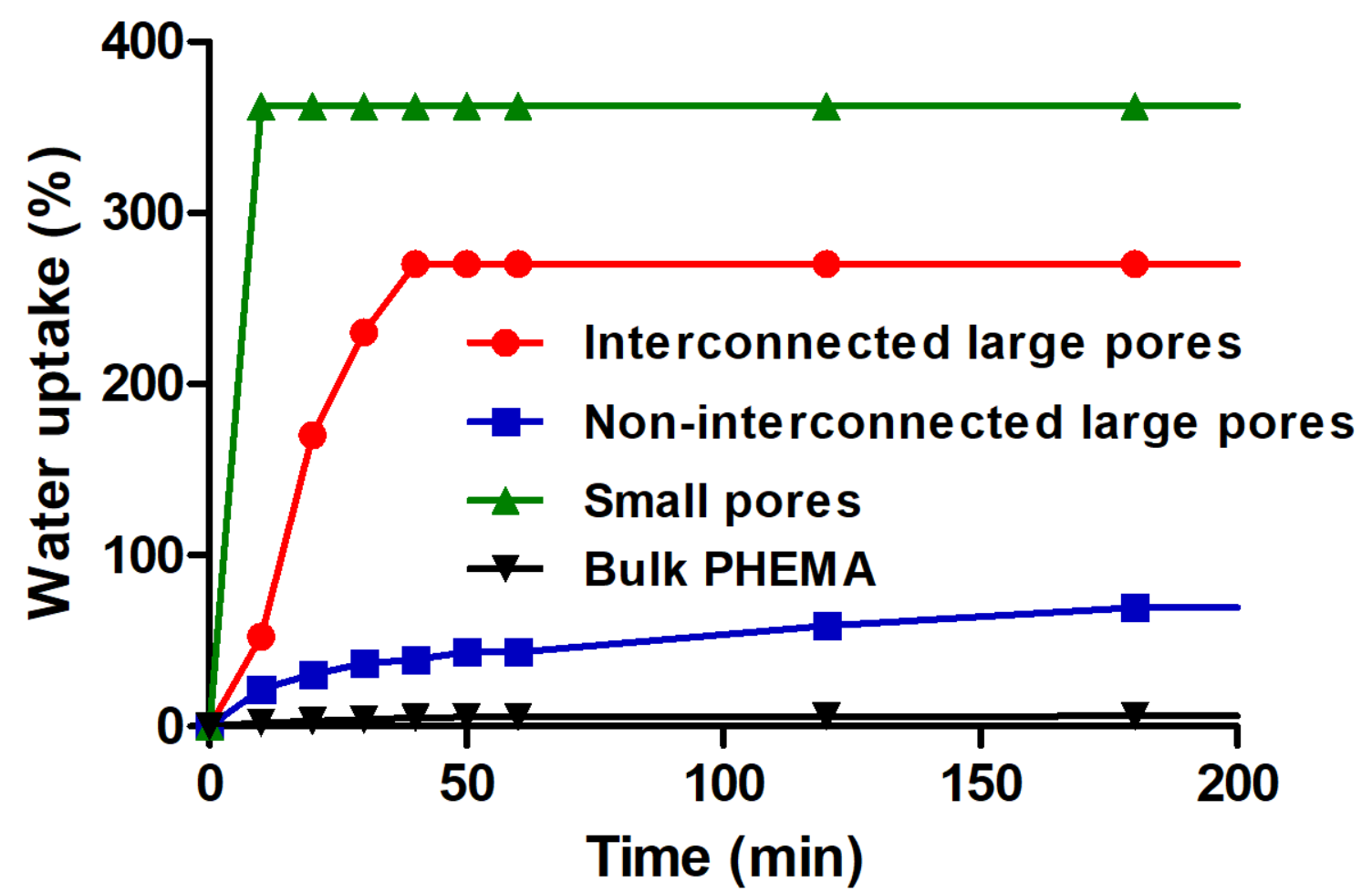

Fig. 12 Water uptake of monoporous networks with interconnected and non-interconnected large pores and small pores as a function of time $(* \mathrm{P}=$ porosity ratio).

\section{Conclusions}

This paper demonstrated the pivotal role of porogenic particle packing on the pore interconnectivity in biporous PHEMA-based materials obtained through the double porogen templating approach. SPS-mediated macroporogen sintering induced a higher compaction of $\mathrm{NaCl}$ particles, thus generating fewer interparticular voids, and eventually afforded a higher porosity ratio of the resulting porous polymeric materials with interconnected macropores. The $\mathrm{NaCl}$ macroporogen size was also determined to be a crucial parameter regarding the porosity features, as increasing macroporogen sizes were associated with increasing porosity ratios. A $\mathrm{X}$-ray computed microtomography $(\mu \mathrm{CT})$ analysis confirmed these results as the $3-\mathrm{D}$ microstructure observed in the case of the material prepared from non-sintered $\mathrm{NaCl}$ particles pointed out some sparse interconnections between adjacent macropores, likely due to very few contact points between neighbor $\mathrm{NaCl}$ particles in the 3-D inorganic template of the porous material. This studies also highlighted the considerable capacity of biporous PHEMA materials to incorporate water compared to bulk and monoporous polymers. Indeed, these complex structures were able to incorporate until $2400 \%$ of water in a few hours, while monoporous counterparts only incorporated $300 \%$. In the literature, it was demonstrated that the water uptake of scaffolds and porous monoliths did not exceed $68 \%$. Moreover, the pore 
interconnectivity increased greatly the water uptake (by a factor of nearly 5-6). As abovementioned, the synchrotron tomography permitted to observe the fine microstructure with 0.65 $\mu \mathrm{m}$ voxel size which is much lower than the scans made by CT $(8 \mu \mathrm{m}$ and $2 \mu \mathrm{m})$. This research permitted to investigate the 3-D microstructure of doubly porous polymeric networks by means of classical $\mu \mathrm{CT}$ and synchrotron $\mu \mathrm{CT}$. The different experimental protocols and imaging devices configuration allowed a precise observation of the morphology of such materials as the pores connectivity and shape. Imaging provided also crucial information about the void/polymeric matrix interfaces which play an important role in transport properties. Three microstructural features were observed : the large pores having the $\mathrm{NaCl}$ particles shape, the polymeric matrix exhibiting the small pores, and thin polymeric walls. However, the quantitative analysis of the porosity was tricky because of the very thin polymeric walls and filaments which made difficult the segmentation step. Finally, some $\mu \mathrm{CT}$ and synchrotron images will be selected as input data for the computation of fluid flow through porous medium in forthcoming experiments. The interconnection in the higher porosity level was demonstrated to be crucial regarding transport properties in such biporous PHEMA-based materials as their water uptake behavior is much more important than that of their non-interconnected counterparts.

\section{Acknowledgments}

This work was supported by a French government grant from ANR within the frame of the national program Investments for the Future ANR-11-LABX-022-01 (LabEx MMCD project). The authors are also indebted to B. Villeroy (ICMPE, CNRS) for his kind technical assistance in the SPS technique.

\section{Compliance with ethical standards}

Conflict of interest The authors declare that they have no conflict of interest.

\section{Funding}

This work has benefited from a French government grant by ANR within the framework of the national program Investments for the Future ANR-11-LABX-022-01 (LabEx MMCD project).

\section{References}


[1] Lav TX, Carbonnier B, Guerrouache M, Grande D (2010) Porous polystyrene-based monolithic materials templated by semi-interpenetrating polymer networks for capillary electrochromatography. Polymer 51(25):5890-5894.

[2] Lav TX, Grande D, Gaillet C, Guerrouache M, Carbonnier B (2012) Porous Poly(styreneco-divinylbenzene) Neutral Monolith: From Design and Characterization to Reversed-Phase Capillary Electrochromatography Applications. Macromol Chem Phys 213(1):64-71.

[3] Yu C, Xu MC, Svec F, Frechet JMJ (2002) Preparation of monolithic polymers with controlled porous properties for microfluidic chip applications using photoinitiated free-radical polymerization. J Polym Sci Pol Chem 40(6):755-769.

[4] Langer R, Vacanti JP (1993) Tissue Engineering. Science 260(5110):920-926.

[5] Nair LS, Laurencin CT (2007) Biodegradable polymers as biomaterials. Prog Polym Sci 32(8-9):762-798.

[6] Auriault JL, Boutin C (1992) Deformable porous-media with double porosity - Quasi-statics .1. Coupling effects. Transport Porous Med 7(1):63-82.

[7] Boutin C, Royer P, Auriault JL (1998) Acoustic absorption of porous surfacing with dual porosity. Int J Solids Struct 35(34-35):4709-4737.

[8] Ly HB, Le Droumaguet B, Monchiet V, Grande D (2016) Tailoring doubly porous poly(2hydroxyethyl methacrylate)-based materials via thermally induced phase separation. Polymer 86138-146.

[9] Santamaria VA, Deplaine H, Mariggio D, Villanueva-Molines AR, Garcia-Aznar JM, Ribelles JLG, et al. (2012) Influence of the macro and micro-porous structure on the mechanical behavior of poly(L-lactic acid) scaffolds. J Non-Cryst Solids 358(23):3141-3149.

[10] Liu XH, Ma PX (2009) Phase separation, pore structure, and properties of nanofibrous gelatin scaffolds. Biomaterials 30(25):4094-4103.

[11] Yang YF, Zhao J, Zhao YH, Wen L, Yuan XY, Fan YB (2008) Formation of porous PLGA scaffolds by a combining method of thermally induced phase separation and porogen leaching. J Appl Polym Sci 109(2):1232-1241.

[12] Kovacic S, Stefanec D, Krajnc P (2007) Highly porous open-cellular monoliths from 2hydroxyethyl methacrylate based high internal phase emulsions (HIPEs): Preparation and void size tuning. Macromolecules 40(22):8056-8060.

[13] Kulygin O, Silverstein MS (2007) Porous poly(2-hydroxyethyl methacrylate) hydrogels synthesized within high internal phase emulsions. Soft Matter 3(12):1525-1529.

[14] Cameron NR (2005) High internal phase emulsion templating as a route to well-defined porous polymers. Polymer 46(5):1439-1449.

[15] Silverstein MS (2014) Emulsion-templated porous polymers: A retrospective perspective. Polymer 55(1):304-320.

[16] Ghosh S, Viana JC, Reis RL, Mano JF (2007) The double porogen approach as a new technique for the fabrication of interconnected poly(L-lactic acid) and starch based biodegradable scaffolds. J Mater Sci-Mater Med 18(2):185-193.

[17] Le Droumaguet B, Lacombe R, Ly H-B, Carbonnier B, Grande D (2014) Novel Polymeric Materials with Double Porosity: Synthesis and Characterization. Macromol Symp 340(1):1827.

[18] Le Droumaguet B, Lacombe R, Ly H-B, Guerrouache M, Carbonnier B, Grande D (2014) Engineering functional doubly porous PHEMA-based materials. Polymer 55(1):373-379.

[19] Ly HB, Le Droumaguet B, Monchiet V, Grande D (2015) Facile fabrication of doubly porous polymeric materials with controlled nano- and macro-porosity. Polymer 7813-21.

[20] Ly H-B, Le Droumaguet B, Monchiet V, Grande D (2015) Designing and modeling doubly porous polymeric materials. Eur Phys J Spec Top 224(9):1689-1706.

[21] Kim UJ, Park J, Kim HJ, Wada M, Kaplan DL (2005) Three-dimensional aqueous-derived biomaterial scaffolds from silk fibroin. Biomaterials 26(15):2775-2785. 
[22] Ghosh S, Viana JC, Reis RL, Mano JF (2007) The double porogen approach as a new technique for the fabrication of interconnected poly(L-lactic acid) and starch based biodegradable scaffolds. J Mater Sci-Mater Med 18(2):185-193.

[23] Gross KA, Rodriguez-Lorenzo LM (2004) Thermally sprayed scaffolds for tissue engineering applications. Key Eng Mater 254961-964.

[24] Gross KA, Rodríguez-Lorenzo LM (2004) Biodegradable composite scaffolds with an interconnected spherical network for bone tissue engineering. Biomaterials 25(20):4955-4962. [25] Audouin F, Heise A (2014) Synthesis of polymer-silica hybrid polyHIPEs by double in situ polymerization of concentrated water in oil emulsion. Polymer 55(1):403-409.

[26] Aligizaki KK (2005) Pore structure of cement-based materials: testing, interpretation and requirements. Taylor \& Francis, New-York

[27] Cartmell S, Huynh K, Lin A, Nagaraja S, Guldberg R (2004) Quantitative microcomputed tomography analysis of mineralization within three-dimensional scaffolds in vitro. J Biomed Mater Res Part A 69A(1):97-104.

[28] Darling AL, Sun W (2004) 3D microtomographic characterization of precision extruded poly-epsilon-caprolactone scaffolds. J Biomed Mater Res Part B Appl Biomater 70B(2):311317.

[29] Lin ASP, Barrows TH, Cartmell SH, Guldberg RE (2003) Microarchitectural and mechanical characterization of oriented porous polymer scaffolds. Biomaterials 24(3):481-489. [30] van Lenthe GH, Hagenmuller H, Bohner M, Hollister SJ, Meinel L, Muller R (2007) Nondestructive micro-computed tomography for biological imaging and quantification of scaffold-bone interaction in vivo. Biomaterials 28(15):2479-2490.

[31] Jones AC, Milthorpe B, Averdunk H, Limaye A, Senden TJ, Sakellariou A, et al. (2004) Analysis of $3 \mathrm{D}$ bone ingrowth into polymer scaffolds via micro-computed tomography imaging. Biomaterials 25(20):4947-4954.

[32] Moore MJ, Jabbari E, Ritman EL, Lu LC, Currier BL, Windebank AJ, et al. (2004) Quantitative analysis of interconnectivity of porous biodegradable scaffolds with microcomputed tomography. J Biomed Mater Res Part A 71A(2):258-267.

[33] Bruchon JF, Pereira JM, Vandamme M, Lenoir N, Delage P, Bornert M (2013) Full 3D investigation and characterisation of capillary collapse of a loose unsaturated sand using X-ray CT. Granul Matter 15(6):783-800.

[34] Flannery BP, Deckman HW, Roberge WG, Amico KL (1987) Three-Dimensional X-ray Microtomography. Science 237(4821):1439.

[35] Kinney JH, Nichols MC (1992) X-Ray Tomographic Microscopy (XTM) Using Synchrotron Radiation. Annu Rev Mater Sci 22(1):121-152.

[36] Lerouge T, Maillet B, Coutier-Murias D, Grande D, Le Droumaguet B, Pitois O, et al. (2020) Drying of a Compressible Biporous Material. Phys Rev Appl 13(4).

[37] Lerouge T, Pitois O, Grande D, Le Droumaguet B, Coussot P (2018) Synergistic actions of mixed small and large pores for capillary absorption through biporous polymeric materials. Soft Matter 14(40):8137-8146.

[38] Mabilleau G, Stancu IC, Honoré T, Legeay G, Cincu C, Baslé MF, et al. (2006) Effects of the length of crosslink chain on poly(2-hydroxyethyl methacrylate) (pHEMA) swelling and biomechanical properties. J Biomed Mater Res Part A 77A(1):35-42.

[39] Refojo MF (1967) Hydrophobic interaction in poly(2-hydroxyethyl methacrylate) homogeneous hydrogel. J Polym Sci Pol Chem 5(12):3103-3113.

[40] Uzun L, Say R, Denizli A (2005) Porous poly(hydroxyethyl methacrylate) based monolith as a new adsorbent for affinity chromatography. React Funct Polym 64(2):93-102.

[41] Gomes ME, Ribeiro AS, Malafaya PB, Reis RL, Cunha AM (2001) A new approach based on injection moulding to produce biodegradable starch-based polymeric scaffolds: morphology, mechanical and degradation behaviour. Biomaterials 22(9):883-889. 
